\title{
Assessment of the Efficacy Therapeutic Milk in Prevention the Complications of Sever Acute Malnutrition in Children 6 - 59 Months at Therapeutic Feeding Center in Public Hospitals in Hodeida City-Yemen
}

\author{
Hanaa Abduh Heba Mohsen Ebrah*, Nadia Abdlrahim Khogali Salih \\ Human Nutrition \& Dietetics, Family Science Department, Faculty of Education, University of Khartoum, Khartoum, Sudan \\ Email: *hanaa.ebrah@gmail.com, nadiakhogaly@hotmail.com
}

How to cite this paper: Ebrah, H.A.H.M. and Salih, N.A.K. (2021) Assessment of the Efficacy Therapeutic Milk in Prevention the Complications of Sever Acute Malnutrition in Children 6 - 59 Months at Therapeutic Feeding Center in Public Hospitals in Hodeida City-Yemen. Food and Nutrition Sciences, 12, 54-63.

https://doi.org/10.4236/fns.2021.121005

Received: November 14, 2020

Accepted: January 25, 2021

Published: January 28, 2021

Copyright $\odot 2021$ by author(s) and Scientific Research Publishing Inc. This work is licensed under the Creative Commons Attribution International License (CC BY 4.0)

http://creativecommons.org/licenses/by/4.0/

\begin{abstract}
Severe acute malnutrition with medical complications is one of the most common causes of morbidity and mortality among children under the age of 5 years. Which can be management by given Therapeutic milk, it is available only at inpatient center at hospitals. When staff and mother managed adequately, the therapeutic milk has highly effective in treating severe malnutrition and prevent any complications that can be developing. So, this study aims to Assess of the Efficacy of Therapeutic milk in Prevention Complications of Severe acute malnutrition 6 - 59 months at therapeutic feeding center. Descriptive, Cross-Sectional, Hospital-based study design was used to conduct the study. The study was carried out at Organization of AL Thora public Hospital at Hodeida city in Yemen. Total coverage 200 children 6 - 59 months of age have Sever Acute Malnutrition with complication which was 14 medical complications and admitted at Therapeutics Feeding Center. Three research tools which used for data collection. The structured face to face Interview questionnaire, anthropometric measurements, and the Structure Observation Check list. The results showed that, the obvious reduction of complication when the Comparison at admission, 1st week and 2nd week are $(40.9 \%$ to $18 \%$ to $7.6 \%)$. There is highly statistically significant relationship between the therapeutic feeding which was given, resolution the complication at 1 st week and 2nd week at $\mathrm{p}<0.05$. Majority of the Sever acute malnutrition children are discharged to Outpatient therapeutic to complete nutritional program. The study concluded that the therapeutic milk which provides in Therapeutic Feeding Center only have highly effective in treating medical complication of sever acute malnutrition in children 6 - 59 months.
\end{abstract}




\section{Keywords}

Hodeida, Malnutrition, TFC, SAM, Complication, Children, Therapeutic Milk

\section{Introduction}

The child with Sever Acute Malnutrition may have poor appetite and suffer presence of medical complications and children with it are at high risk of death as appear by clinical features of infection, metabolic disturbance, severe edema, hypothermia, vomiting, severe dehydration, severe anemia or a lack of appetite, requiring to admission to inpatient treatment which also called Therapeutics Food Center (TFC) and require treatment of both the complication and their routine dietary and medicine section [1].

The management of Sever wasting (marasmus) and Nutritional edema (kwashiorkor) follows the same principles [2].

In the process of treating, the focus of initial management is to prevent death while stabilizing the child. The first step is to check the child for emergency signs and provide emergency treatment as necessary that must be done very quickly [3]. With Start cautious feeding with milk F-75 (Formula 75) is the milk-based diet recommended by the WHO for the stabilization of children with SAM in inpatient care. Energy and protein content $(75 \mathrm{kcal} / 100 \mathrm{ml}$ and $0.9 \mathrm{~g}$ protein/100 $\mathrm{ml}$ respectively) and total feed volume are restricted to prevent heart failure, osmotic diarrhea and worsening of edema. It promotes recovery of normal metabolic function and nutrition-electrolytic balance [4], once medical problems and edema are resolving, blood sugars are stable and appetite has returned, the child is ready for the transition to the rehabilitation phase. The formula F-75 is gradually replaced with F-100 $(100 \mathrm{kcal} / 100 \mathrm{ml})$ is the milk-based diet recommended by WHO for the rehabilitation of children with SAM after stabilization in inpatient care, for children with SAM in transition or children who remain in inpatient care until full recovery [3].

RUTFs are high energy and protein foods made from peanut paste, milk powder, oil and sugar, enriched with electrolytes, vitamins and minerals including iron [4].

Therapeutic feeding is very important and is available only at inpatient center at hospitals. When staffed and mother managed adequately, the therapeutic milk has highly effective in treating sever malnutrition and prevent any complications can be developed [5].

\section{Materials and Methods}

\subsection{Study Design}

Descriptive Cross-Sectional, Hospital-based study design was conducted to assess efficacy of the Therapeutic milk in prevention of the complications of SAM 
for all children 6 - 59 months of age have Sever Acute Malnutrition who admitted in TFC at Organization of AL Thora public Hospital in Hodeida City-Yemen was conducted from February 2019 for duration of approximately 8 months.

\subsection{Data Collection Technique and Tool}

Three research tools which used for data collection. They are the structured face to face Interview questionnaire, anthropometric measurements, and the Structure Observation Check list:

\section{A. The Structured face to face Interview questionnaire}

The Interview questionnaire, consist of four parts:

Part one: Demographic data of childlike gender, age, family residency.

Part two: About the socioeconomic status like parent education, family members, household condition, sanitation, family income.

Third part: Was about the child's eating information and child's health status like breastfeeding, weaning age, kind of meals.

Fourth part: Was about signs and symptoms of sever acute malnutrition and presence of complications and type of complications.

\section{B. Anthropometric Measurements}

Weight of children was measure in $(\mathrm{kg})$, and the height/length in $(\mathrm{cm})$, MUAC and presence or absence of bilateral edema and appetite assessed. The anthropometric measurements were taken by the researcher himself.

\section{The Structure Observation Check list}

the Structure Observation Check list also constructed by the researcher and consist of daily follow up of therapeutic formula meals, type, amount, frequency, Ability to drink orally or NG tube, presence of diarrhea and vomiting and frequency, resolve of complication which present from date of admission and appear new complication. It was composed of main 2 observed items first item daily follow up of therapeutic formula ranged from $1-12$ parts and the second item consist of elements of complications of Sever Acute Malnutrition ranged from 1 - 11 parts.

\subsection{The Data Collection Procedure}

\section{A. The Structured face to face Interview Questionnaire:}

The variables to be assessed by the interview questionnaire were as follows:

- Demographic data of childlike gender, age, family residency.

- The socioeconomic status like parent education, family members, household condition, sanitation, family income.

- The child's eating information and child's health status like breastfeeding, weaning age, kind of meals.

- The signs and symptoms of sever acute malnutrition and presence of complications and type of complications.

\section{B. Anthropometric Measurements}

The Anthropometric Measurements were taken by the researcher and include: Weight of children was measure in $(\mathrm{kg})$, nude weight was recorded by using a 
Beam Span scale and taken at admission and repeated daily in same time at 9 am.

Height/length in $(\mathrm{cm})$, and taken at admission.

Mid Upper Arm Circumference (MUAC) was taken at admission and repeated weekly.

Assessed presence or absence of bilateral edema.

Assessed appetite at admission.

\section{The Structure Observation Check list}

The children with SAM were observed closely by the researcher daily follow up of therapeutic formula and complication resolution.

\section{Ethical consideration}

Ethical approval for this study was received from the Head of Organization of ALThora Hospital in Hodeida city and nursing head of TFC (inpatient ward).

No financial incentives were provided and the participants were not under pressure of any sort to take part in the study, Respondents have the right to withdraw any time if they so wished.

To ensure confidentiality and anonymity of the participants no names were recorded in the questionnaire and the observation check list during data collection and reporting.

\section{Problems and Limitations of the study}

There are many sensitive obstacles which was faced the researcher during the working of the study, due to the culture and believes of the parents, which lead them to refuse the participation of their children in the study. However, the following obstacles are the most important that may face the researcher during the study:

1) The limited resources such as reports, statistical data, books, research published and journals in the area of research in Yemen.

2) Lack of fund, it is the major limitation of this study is Material costs.

3) Full interruption of the Electricity power supply.

4) Temporary \& Full interruption of the Internet network.

5) Lack of cooperation from some officials in public hospital.

\section{Strength of the study}

This research hopefully will support and encourage use Therapeutic Formula Milk for children with SAM to prevent complication.

The mother information will be improving when taught and education by the researcher.

Morbidity \& Mortality will be reducing in children with SAM.

It is will be applicable in the Ministry of health hospitals.

\section{Result}

Figure 1 Shows all the sample 100\% are have loss of appetite and from other side all the sample are not have Open skin lesion and Eye signs of vitamin A deficiency except few $9 \%$ and $2.5 \%$.

Figure 2 shows that more than half of the sample $59.20 \%$ and $56.60 \%$ are loss 
of appetite and LRT infection. And onle few of the sample $4.70 \%, 2.50 \%$ and $2.30 \%$ are shock, eye signs vit-A deficiency and convulsion.

Figure 3 shows that more than quarter $27.50 \%$ and $26.10 \%$ are LRT infection and open skin lesion. The loss of appetite is decrease to $19.80 \%$. Completely resolution $(0 \%)$ is intractable vomiting, convulsion and hypothermia.

Table 1 shows obvious resolution the most of the complication when compare between complication of sever acute malnutrition at admission, 1st week and 2nd week.

Table 1. Comparison between complication of sever acute malnutrition at admission, 1 st week and 2 nd week.

\begin{tabular}{cccc}
\hline Medical complication & At admission (\%) & At 1st week (\%) & At 2nd week (\%) \\
\hline loss of appetite & $100 \%$ & $59.2 \%$ & $19.8 \%$ \\
Intractable vomiting & $52 \%$ & $7.9 \%$ & $0 \%$ \\
Convulsions & $12.5 \%$ & $2.3 \%$ & $0 \%$ \\
Lethargy, not alert & $73.5 \%$ & $24.8 \%$ & $4.3 \%$ \\
Unconsciousness, shock & $13 \%$ & $4.7 \%$ & $2.5 \%$ \\
Hypoglycemia & $31.5 \%$ & $6.4 \%$ & $0.5 \%$ \\
High fever & $74 \%$ & $18 \%$ & $0.8 \%$ \\
Hypothermia & $23.5 \%$ & $8.3 \%$ & $0 \%$ \\
Diarrhea & $61.5 \%$ & $17.1 \%$ & $3.1 \%$ \\
Dehydration & $21.5 \%$ & $7.5 \%$ & $3.7 \%$ \\
LRT infection & $63.5 \%$ & $56.6 \%$ & $27.5 \%$ \\
Severe anemia & $35 \%$ & $28.1 \%$ & $13.7 \%$ \\
Eye signs vit-A deficiency & $2.5 \%$ & $2.5 \%$ & $4.5 \%$ \\
Open skin lesion & $9 \%$ & $8.7 \%$ & $26.1 \%$ \\
\hline
\end{tabular}

Table 1 shows the comparison between complication of sever acute malnutrition at admission, 1st week and 2nd week.

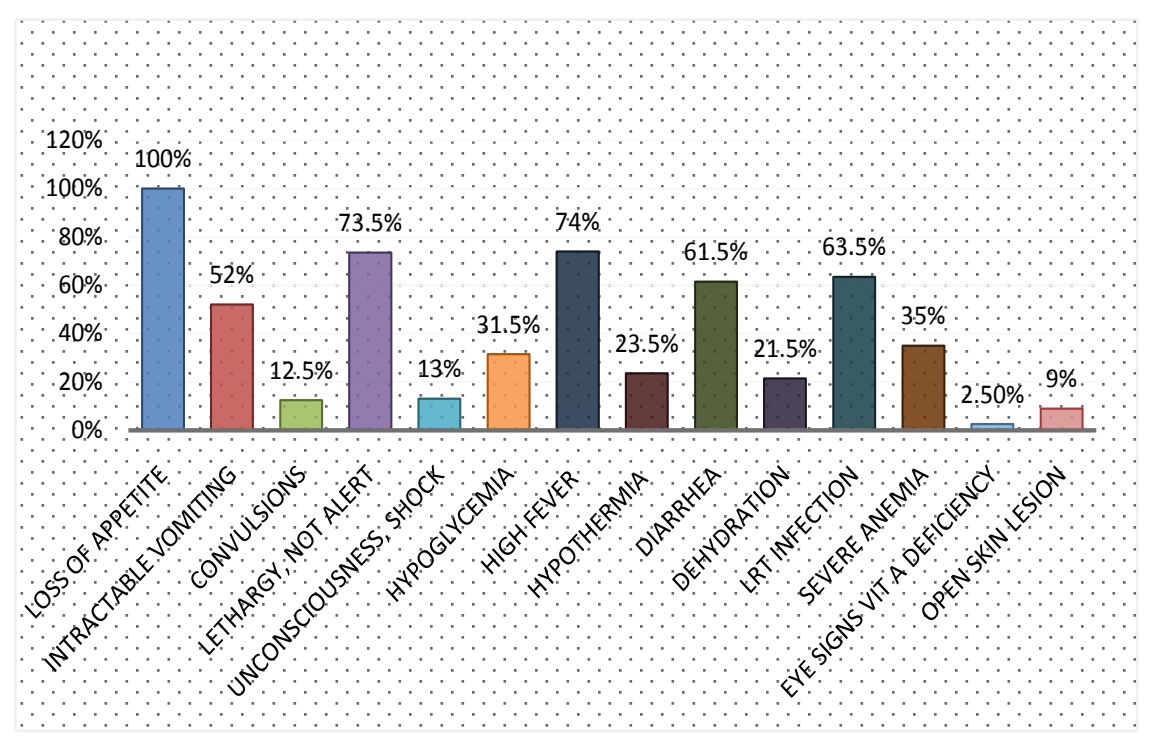

Figure 1. Complication of sever acute malnutriton at admission. 


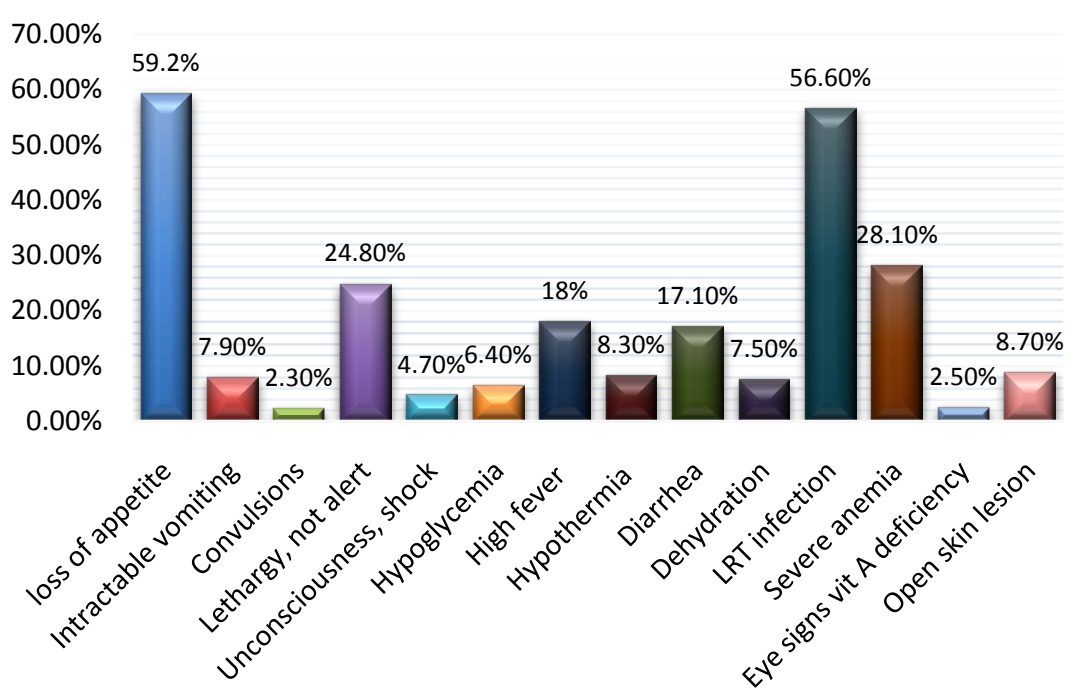

Figure 2. Complication of sever acute malnutriton at 1st week of admission.

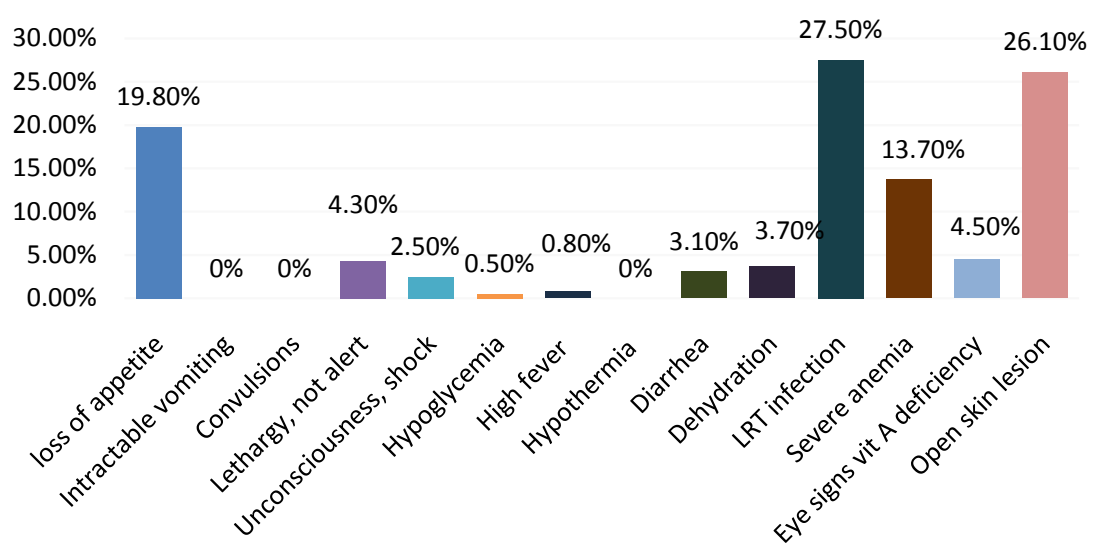

Figure 3. Complication of sever acute malnutriton at 2 nd week of admission.

\section{Discussion}

When the children are assess at the time of admission for the associated medical complications, it is found that all sample SAM children (100\%) have the 14 medical complication and all the sample (100\%) are have anorexia, three quarter of sample (74\%), (73.5\%) are high fever and lethargy, (59.3\%) of diarrhea in SAM children are more than 10 time in day and (21.5\%) are dehydration, half of the sample (52\%) are have Intractable vomiting, about sever anemia and hypoglycemia more than quarter of sample (35\%) and (31.5\%) they have those complications, quarter of the sample (23.5\%) are have, shock and Convulsions eighth of sample (13\%) and (12.5\%) they have those complications, all the SAM children are not have open skin lesion and Eye signs of vitamin A deficiency except few $(9 \%)$ and $(2.5 \%)$. 
So the fever and lethargy most prevalent complication in sever acute malnutrition children followed closely by diarrhea and lower respiratory tract infection then by Intractable vomiting and followed by sever anemia and hypoglycemia (see Figure 1).

About resolution of sever acute malnutrition complications during 1stweek of admission (see Figure 2), more than half (59.20\%) and (56.60\%) are loss of appetite and LRT infection. More than quarter (28.10\%) and around quarter $(24.80 \%)$ are severe anemia and lethargy. More than eight (18\%) and (17.10\%) are high fever and diarrhea. $(8.30 \%)$ and $(8.70 \%)$ are hypothermia and open skin lesion. (7.90\%) and $(7.50 \%)$ are intractable vomiting and dehydration. $(6.40 \%)$ is hypoglycemia. (4.70\%) is shock. $(2.50 \%)$ and $(2.30 \%)$ are eye signs vit-A deficiency and convulsion. While About resolution of sever acute malnutrition complications during 2nd week of admission (see Figure 3), more than quarter $(27.50 \%)$ and $(26.10 \%)$ are LRT infection and open skin lesion. The loss of appetite is decrease to $(19.80 \%)$. Severe anemia is $(13.70 \%)$. $(4.50 \%)$ and $(4.30 \%)$ are eye signs vit-A deficiency and lethargy. (3.70\%) and $(3.10 \%)$ are dehydration and diarrhea. (2.50\%) shock. $(0.8 \%)$ and $(0.5 \%)$ are high fever and hypoglycemia. Completely resolution ( $0 \%)$ is intractable vomiting, convulsion and hypothermia.

Table 1 represent the comparison between complications of sever acute malnutrition at admission, 1st week and 2nd week. All sample (100\%) are loss of appetite, improve to half (59.2\%) in 1st week and become less than quarter $(19.8 \%)$ in 2 nd week. Three quarter $(73.5 \%)$ and $(74 \%)$ of the sample are Lethargy and High fever at admission, which decrease to quarter (24.8\%), (18\%) in 1 st week and improve to $(4.3 \%),(0.8 \%)$ in the 2 nd week. More than half (61.5\%) and $(63.5 \%)$ of the sample are Diarrhea and LRT infection which decreases (17.1\%) and (56.6) in 1st week and reach to (3.1\%) and (27.5\%). Intractable vomiting, Convulsions and Hypothermia completely resolution in 2nd week which are (52\%), (12.5\%) and (23.5\%) at admission. More than quarter (31.5\%) and (35\%) of the sample are Hypoglycemia and Severe anemia which improve in 1st week to $(6.4 \%),(28.1 \%)$ and in 2 nd week to $(0.5 \%),(13.7 \%)$. About quarter (21.5\%) of the sample is Dehydration at admission and improve to (3.7\%) at the 2nd week.

The overall comparisons between complications of sever acute malnutrition at admission, 1st week and 2nd week. The total of complication at admission, 1st week and 2 nd week are ( $40.9 \%$ to $18 \%$ to $7.6 \%)$. The overall mean for complication at admission, 1 st week and 2 nd week are (41 to 18.01 to 7.61$)$. $\mathrm{P}$ value $=$ $0.000<0.05$ correlation coefficient $(9.1241$ ) (see Table 2).

About the correlations between complications of sever acute malnutrition at 1 st week and therapeutic feeding which given. $\mathrm{p}=0.004<0.05$; correlation coefficient (4.24289). There is highly statistically significant relationship between the therapeutic feeding which given and resolution the complication at 1 st week (see Table 3) moreover, in 2nd week $\mathrm{p}=0.001<0.05$; correlation coefficient (5.104) 
also there is highly statistically significant relationship between the therapeutic feeding which given and resolution the complication at 2 nd week (see Table 4).

In Table 5 Majority of the sample (90.5\%) discharge to Out Therapeutic Patient (OTP) to complete nutritional program. About (5\%) of the SAM children are dead which is within the acceptable limits $(<10 \%)$ according to WHO stander for reference values of main indicators [6], (2.5\%) are have Cereal sensation and given free glutin formula, (1\%) are medical transfer to another medical service and also (1\%) escape from treatment.

Table 2. Overall comparison between complication of sever acute malnutrition at admission, 1 st week and 2nd week.

\begin{tabular}{cccccccc}
\hline Medical complication & $(\%)$ & Mean & SD & Min & Max & correlation & P \\
coefficient & value \\
At admission & $40.9 \%$ & 41 & 29.8573 & 3 & 100 & & \\
\hline At $1^{\text {st }}$ week & $18 \%$ & 18.01 & 18.662 & 2.30 & 59.20 & & \\
At 2 $2^{\text {nd }}$ week & $7.6 \%$ & 7.61 & 9.9081 & 0 & 27.50 & & \\
\hline
\end{tabular}

Table 2 Reveals the overall comparison between complication of sever acute malnutrition at admission, 1st week and 2 nd week. P value $<0.05$ is a highly is significant.

Table 3. Correlation between complication of sever acute malnutrition at 1st week and therapeutic feeding.

\begin{tabular}{|c|c|c|c|c|}
\hline & Mean & $\mathrm{SD}$ & \multirow{2}{*}{$\begin{array}{l}\text { correlation } \\
\text { coefficient }\end{array}$} & \multirow{2}{*}{$\begin{array}{c}\mathrm{P} \\
\text { value }\end{array}$} \\
\hline F75 & 29.75 & 37.6015 & & \\
\hline F100 & 22.7143 & 20.7954 & \multirow{5}{*}{4.24289} & \multirow{5}{*}{0.000} \\
\hline RUTF & 6.8214 & 7.4462 & & \\
\hline & & & & \\
\hline F100 + RUTF & 1.0357 & 1.0463 & & \\
\hline Complication in 1 st week & 18.0071 & 18.662 & & \\
\hline
\end{tabular}

Table 3 shows the correlation between complication of sever acute malnutrition at 1st week and therapeutic feeding $\mathrm{P}$ value $<0.05$ is a highly is significant.

Table 4. Correlation between complication of sever acute malnutrition at 2nd week and therapeutic feeding.

\begin{tabular}{ccccc}
\hline & Mean & SD & $\begin{array}{c}\text { correlation } \\
\text { coefficient }\end{array}$ & $\begin{array}{c}\text { P } \\
\text { value }\end{array}$ \\
\hline F75 & 29.75 & 37.6015 & & \\
FUTF & 22.7143 & 20.7954 & & \\
F100+RUTF & 6.8214 & 7.4462 & & \\
Complication in 2nd week & 1.0357 & 1.0463 & & \\
\hline
\end{tabular}

Table 4 shows the correlation between complication of sever acute malnutrition at 2 nd week and therapeutic feeding $\mathrm{P}$ value $<0.05$ is a highly is significant. 
Table 5. Outcome of sever acute malnutrition children according to type of discharge from TFC.

\begin{tabular}{ccc}
\hline Type of discharge from TFC & Frequency & Percent \\
\hline Discharge to OTP & 181 & $90.5 \%$ \\
Dead & 10 & $5 \%$ \\
Cereal sensation (free gluten formula) & 5 & $2.5 \%$ \\
Medical transfer & 2 & $1 \%$ \\
Escape & 2 & $1 \%$ \\
Total & 200 & $100 \%$ \\
\hline
\end{tabular}

Table 5 shows that the majority of the sample $90.5 \%$ are discharged to OTP, $5 \%$ are dead and only $1 \%$ of the sample are medical transfer and escape.

\section{Conclusion}

Based on the result of the study, the researcher concluded that. All the studied children are having medical complications at admission and the most common complication are anorexia, high fever, lethargy, lower respiratory tract infection and diarrhea. The obvious reeducation of complication when the Comparison at admission, 1st week and 2nd week. There is highly statistically significant relationship between the therapeutic feeding which given and resolution the complication at 1st week and 2nd. Majority of the SAM children are discharged to OTP to complete nutritional program.

\section{Acknowledgements}

In this study my acknowledgement will be directed to all SAM children mothers in the assigned hospitals who helped me in conducting this study and to everybody facilitate this work to me.

\section{Conflicts of Interest}

The authors declare no conflicts of interest regarding the publication of this paper.

\section{References}

[1] Golden, M. and Grellety, Y. (2011) Guidelines for the Integrated Management of Severe Acute Malnutrition: In- and Out-Patient Treatment. ACF International, Paris.

[2] Ashworth, A., Khanum, S. and Schofield, C. (2003) Guidelines for the Inpatient Treatment of Severely Malnourished Children. World Health Organization, Geneva.

[3] WHO (2007) Community-Based Management of Severe Acute Malnutrition. World Health Organization, the World Food Programme, the United Nations System Standing Committee on Nutrition and the United Nations Children's Fund.

[4] Kramer, C.V. and Allen, S. (2015) Malnutrition in Developing Countries. Paediatrics \& Child Health, 25, 422-427. https://doi.org/10.1016/j.paed.2015.04.002 
[5] Collins, S. (2007) Treating Severe Acute Malnutrition Seriously. Archives of Disease in Childhood, 92, 453-461. https://doi.org/10.1136/adc.2006.098327

[6] WHO (2012) Training Course on Inpatient Management of Severe Acute Malnutrition. Version 1st Edition, Republic of Yemen Ministry of Public Health and Population, World Health Organization. 